\title{
ESOFAGITES EM PACIENTES COM SÍNDROME DE IMUNODEFICIÊNCIA ADQUIRIDA. Estudo histológico e imunoistoquímico
}

\author{
Ana Paula Aguiar VIDAL', Vera Lucia Nunes PANNAIN² e Adriana Marques Caroli de Freitas BOTTIN0²
}

RESUMO - Racional - A maioria dos pacientes com síndrome da imunodeficiência adquirida cursa com sintomas gastrointestinais ao longo da sua evolução. A alta prevalência e morbidade das esofagites nesses pacientes são amplamente reconhecidas. Objetivos - Graduar, histologicamente, as esofagites; identificar os agentes associados, tais como Candida $s p_{2}$ citomegalovírus, herpes vírus e micobactérias; identificar, através da imunoistoquímica, os seguintes agentes: citomegalovírus, herpes vírus I e II, vírus Epstein-Barr, vírus do papiloma humano e vírus da imunodeficiência adquirida; verificar a contribuição da imunoistoquímica para o diagnóstico dos agentes infecciosos; verificar a associação entre os achados histológicos e endoscópicos; verificar a relevância do número de fragmentos na caracterização dos agentes etiológicos. Métodos - Estudaram-se, retrospectivamente, biopsias esofagianas em 227 pacientes com síndrome da imunodeficiência adquirida. Utilizaram-se as colorações de hematoxilina e eosina, PAS ("periodic acid of Schiff"), prata de Grocott e Ziehl-Nielsen, assim como a imunoistoquímica para a detecção de infecções por agentes oportunistas. Aspectos endoscópicos também foram avaliados. Resultados - A esofagite inespecífica acentuada, localizada no terço inferior, foi o tipo mais freqüente. A Candida sp foi o agente mais encontrado, seguida de citomegalovírus, herpes vírus e micobactérias. A presença de placa e ulceração sugeriu o diagnóstico de candidíase e esofagite por citomegalovírus, respectivamente. O herpes vírus I não foi encontrado isolado e sim associado ao herpes vírus II. Não houve imunorreatividade para o vírus Epstein-Barr e o vírus da imunodeficiência adquirida. O número de fragmentos nas amostras não influenciou na detecção do agente etiológico. Conclusão - Os achados endoscópicos de lesão em placa ou de úlcera estão associados com os diagnósticos de Candida sp e citomegalovírus, respectivamente. O emprego da técnica de imunoistoquímica auxilia no diagnóstico das esofagites virais e torna possível detectar o citomegalovírus em esôfagos normais à endoscopia e/ou ao exame histopatológico.

DESCRITORES - Esofagite. Síndrome de imunodeficiência adquirida. Imunoistoquímica.

\section{INTRODUÇÃO}

Os sinais e sintomas relacionados ao sistema digestório são freqüentes em pacientes com síndrome da imunodeficiência adquirida (AIDS), sendo referidos em $50 \%$ a $90 \%$ dos casos, com predominância de colites seguidas de esofagites ${ }^{(14,16,19)}$. Nos pacientes com AIDS, é de fundamental importância o estudo das formas de apresentação e a caracterização do agente etiológico das esofagites infecciosas, tendo em vista a sua morbidade e contribuição para a redução da sobrevida ${ }^{(1,10,12,25,49)}$.

Os agentes infecciosos mais comumente encontrados são Candida $s^{(3)}$, os vírus: citomegalovírus (CMV), herpes simples (HSV) ${ }^{(4,32,38)}$, Epstein-Baar (EBV) ${ }^{(44)}$, papiloma vírus humano $(\mathrm{HPV})^{(48)}$, vírus da imunodeficiência humana (HIV) ${ }^{(29)}$, as micobactérias ${ }^{(18)}$ e os protozoários Cryptosporidium sp e Pneumocystis carinii( ${ }^{(25)}$. As infecções podem apresentar-se isoladas ou concomitantes ${ }^{(4)}$.
A endoscopia digestiva é o procedimento de eleição para o diagnóstico das lesões esofagianas. Trata-se do método mais sensível e específico, que permite a retirada de material para exames laboratoriais ${ }^{(7,33)}$.

A disponibilidade de medicamentos anti-retrovirais mais eficientes diminuiu a incidência das infecções oportunistas no sistema digestório nesses pacientes, as quais têm se mantido em remissão mesmo sem o uso de antibióticos profilaticamente ${ }^{(31,33)}$. Entretanto, a interrupção do tratamento é problema freqüente em países em desenvolvimento, o que torna essa avaliação difícil $^{(9,13,53)}$. A série aqui apresentada tem o perfil das esofagites antes da introdução da terapia anti-retroviral com os poliquimioterápicos.

\section{Objetivos}

Foram estudadas biopsias esofagianas de pacientes com AIDS com os objetivos de: graduar histologicamente as esofagites, identificar os agentes associados, tais como

\footnotetext{
Trabalho realizado no Departamento de Patologia / Serviço de Anatomia Patológica do Hospital Universitário Clementino Fraga Filho da Universidade Federal do Rio de Janeiro, RJ.

'Serviço de Anatomia Patológica do Hospital Universitário Clementino Fraga Filho da Universidade Federal do Rio de Janeiro; ${ }^{2}$ Departamento Patologia da Faculdade de Medicina da Universidade Federal do Rio de Janeiro, RJ.

Correspondência: Dra. Ana Paula Aguiar Vidal - Rua Dezenove de fevereiro, 62/701 - Botafogo - 22280-030 - Rio de Janeiro, RJ. E-mail: apavidal@hucff.ufrj.br
} 
Candida sp, citomegalovírus, herpes vírus e micobactérias, identificar, através da imunoistoquímica, os agentes: CMV, HSV I e II, EBV, HPV e HIV, verificar a contribuição da imunoistoquímica para o diagnóstico dos agentes infecciosos, verificar a associação entre os achados histológicos e endoscópicos, assim como a influência do número de fragmentos na caracterização dos agentes etiológicos.

\section{MÉTODOS}

Foram analisadas, retrospectivamente, biopsias de esôfago de 227 pacientes com AIDS, registrados no Serviço de Anatomia Patológica do Hospital Universitário Clementino Fraga Filho da Universidade Federal do Rio de Janeiro, RJ, realizadas no período de 1990 a 1995.

As amostras foram analisadas utilizando-se as colorações de hematoxilina-eosina (H-E), ácido periódico de Schiff (PAS), Ziehl-Nielsen e a impregnação pela prata de Grocott. $\mathrm{Na}$ graduação histológica da inflamação esofagiana utilizaram-se os critérios definidos por BONACINI et al. ${ }^{(4)}$, que consideram a relação entre a área total do espécime e a área ocupada pelo infiltrado inflamatório, atribuindo os seguintes graus: 0 (normal), ausência de inflamação; 1 (leve): corresponde à ocupação de até $15 \%$ da área; 2 (moderada): até 50\%; 3 (acentuada): mais de $50 \%$. O diagnóstico etiológico das esofagites foi realizado quando se encontraram microorganismos como: esporos ou pseudohifas compatíveis com Candida sp nas colorações de H-E, PAS ou prata; micobactérias na coloração de ZiehlNielsen ou efeitos citopáticos virais seguindo as definições morfológicas já estabelecidas para CMV por Cowdry ${ }^{(15,17)}$, $\mathrm{HSV}^{(38)} \mathrm{e} \mathrm{HPV}^{(8,47)}$. As formas de inclusões atípicas encontradas em alguns casos de CMV quando as células apresentavam: cariomegalia (cerca de 2 a 3 vezes o tamanho normal) sem evidência de inclusão nuclear, anfofilia e grânulos eosinofílicos citoplasmáticos, foram incluídas nos diagnósticos desta casuística como suspeitas, porém não conclusivas para CMV, segundo descrito na literatura ${ }^{(38)}$.

Submeteram-se 215 casos a pesquisa pela imunoistoquímica. A seleção dos casos teve como critério a disponibilidade de material no bloco de parafina para a confecção de cortes de forma a minimizar os erros de amostragem. Utilizaram-se anticorpos (Ac) Dako A/S DK. Os agentes virais estudados são abaixo especificados: Ac anti-citomegalovírus, monoclonal clone DDG9, CCH2, soro anti-camundongo na diluição de 1:30; Ac anti-HSV tipo I monoclonal, soro anti-coelho na diluição de 1:800; Ac anti-HSV tipo II monoclonal soro anticoelho na diluição de 1:800; Ac anti-papiloma vírus policlonal bovino, clone BPV-1, soro anti-camundongo, pré-diluido; Ac anti-EBV, monoclonal, clone LMP, CSI-4 soro de camundongo, na diluição de 1:400; Ac anti-HIV, monoclonal, clone p24, Kal-1, soro anti-camundongo, na diluição de 1:5. Os cortes foram desparafinados e hidratados. A recuperação antigênica ocorreu em solução de ácido cítrico a $0,01 \mathrm{M}, \mathrm{pH}$ 6.0, em duas incubações de 9 minutos em forno de microondas. A peroxidase endógena foi bloqueada em solução de peróxido de hidrogênio a $6 \%$ em etanol, em dois banhos de 5 minutos.
O bloqueio da reação inespecífica foi feito com albumina bovina diluída a $1 \%$ em TBS por 20 min em estufa a $37^{\circ} \mathrm{C}$. Os cortes foram incubados com os anticorpos em câmara úmida a $4^{\circ} \mathrm{C}$ por 18 horas. Seguiu-se a incubação com Ac secundário, componente do conjunto ABC Vectastain pK4001 e pK 4002 (Vector, EUA) conjugado com biotina IG de cavalo anti-camundongo ou IG suíno anti-coelho de acordo com o Ac primário, na diluição de $1: 200$, em câmara úmida a $37^{\circ} \mathrm{C}$, por 30 minutos. Entre as incubações foram feitas lavagens com tampão $\mathrm{PBS}, \mathrm{pH}$ 7.4. A reação foi detectada através da incubação com o sistema estreptoavidina-biotina-peroxidase (ABC Vector duet mouse/rabbit-Vector, EUA) na diluição de 1:200 em PBS. A revelação deu-se em substrato cromógenoDAB $60 \mathrm{mg} \%$ em PBS $+2 \mathrm{~mL}$ de peróxido de hidrogênio a $10 \%$ por 5 minutos a $37^{\circ} \mathrm{C}$. Os cortes foram contra corados pela hematoxilina de Harris.

Os dados de gênero, idade e achados endoscópicos foram obtidos através de consulta aos prontuários e correlacionados aos achados histológicos.

De acordo com o número de fragmentos presentes nas amostras, foram estabelecidos dois grupos: um deles, menor ou igual a 3 (1-3) e outro, maior que 3 (4-6) fragmentos.

A análise estatística foi realizada pelo teste de qui-quadrado ou pelo teste exato de Fisher sendo considerados significantes os valores de $P<0.05$.

\section{RESULTADOS}

Entre os 227 pacientes com biopsias esofagianas, 181 (79,7\%) eram do gênero masculino e 46 (20,3\%) do feminino, com proporção de 4:1. A idade média foi de 35 anos para os dois grupos. Foram identificados critérios histológicos para o diagnóstico de esofagite em 209 casos, sendo distribuídos quanto ao grau de inflamação, da seguinte forma: 53 (25,3\%) grau I, 37 (17,7\%) grau II e $119(57 \%)$ grau III.

Ao exame endoscópico havia alteração da mucosa esofagiana em 223 pacientes (98,2\%). A distribuição dos aspectos endoscópicos mais freqüentemente encontrados está descrita na Tabela 1. Encontraram-se as seguintes associações significativas entre o diagnóstico histopatológico e os aspectos endoscópicos: esofagite por Candida $s p$ e placas em $89 \%(P<0,0001)$, esofagite por Candida sp e enantema em $49 \%(P=0,05)$, esofagite por CMV e úlceras em $67 \%$ $(P=0,01)$ e esofagite inespecífica e úlceras em $58 \%$ dos casos $(P=0,013)$.

TABELA 1. Aspectos endoscópicos isoladamente ou em associação

\begin{tabular}{lc}
\hline Aspecto endoscópico & $\mathbf{n}$ \\
\hline Placa & 109 \\
Úlcera & 108 \\
Enantema & 89 \\
Erosão & 31 \\
Nódulo & 7 \\
Pólipo & 6 \\
Normal & 4 \\
\hline
\end{tabular}


A distribuição dos diagnósticos da endoscopia está descrita na Tabela 2. Houve associação significativa entre o diagnóstico endoscópico e histológico para: esofagite $(P=0,04)$, Candida $s p(P<0.0001)$ e CMV $(P=0,045)$. Outra importante associação significativa observada foi a suspeita de CMV à endoscopia e o diagnóstico histopatológico sugestivo de vírus $(P=0,001)$.

$\mathrm{Na}$ análise das colorações de rotina, em 111 casos foi identificado o agente etiológico. Destes, ocorreu associação de agentes em 10 casos. A esofagite inespecífica $(\mathrm{n}=97)$ e a esofagite por Candida $s p$, isolada ou em associação, $(\mathrm{n}=70)$ foram as mais freqüentes, enquanto que a esofagite viral mais freqüente foi pelo CMV (Figura 1), isolado ou em associação $(\mathrm{n}=23)$ (Tabela 3$)$.

TABELA 2. Diagnósticos endoscópicos referidos isoladamente ou em associação

\begin{tabular}{lc}
\hline Diagnóstico endoscópico & $\mathrm{n}$ \\
\hline Inespecífico & 78 \\
Candida sp & 70 \\
Não referido & 54 \\
Citomegalovírus & 20 \\
Normal & 4 \\
Herpes vírus & 3 \\
Micobacteriose & 1 \\
Papiloma & 1 \\
\hline
\end{tabular}

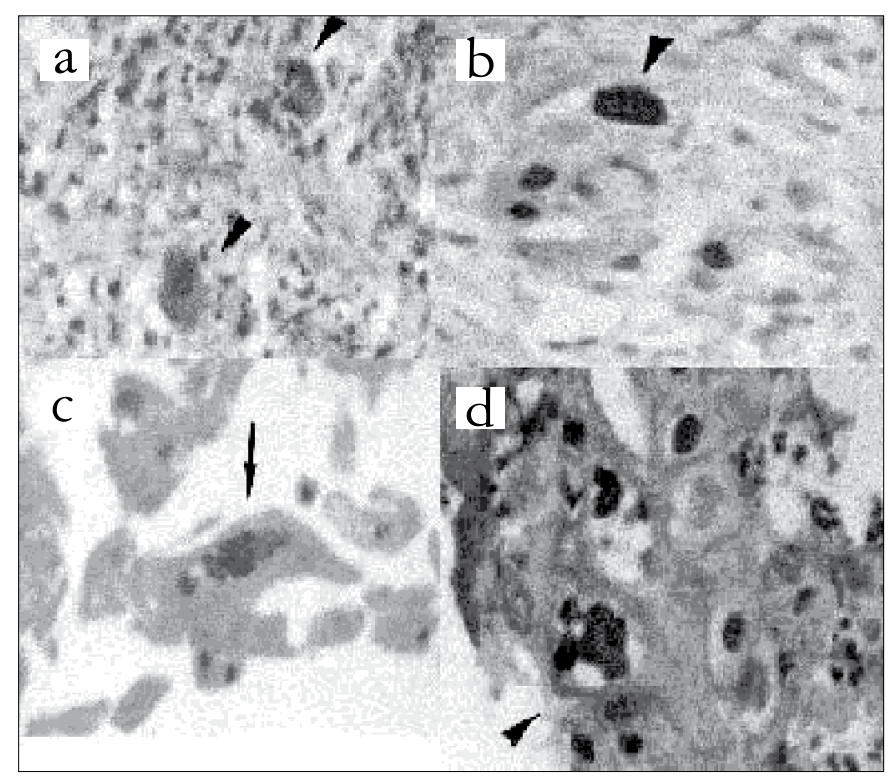

FIGURA 1. a. inclusões citomegálicas (CMV)-H-E 40x; b. imunoistoquímica para CMV - marcação positiva nuclear e citoplasmática; c. inclusões por herpes simples (HSV) - HE 40x; d. imunoistoquímica para HSV - marcação positiva nuclear

Quando associados os resultados obtidos à imunoistoquímica com as técnicas convencionais de coloração, houve mudança no perfil dos diagnósticos. No total de biopsias estudadas, passou-se a ter critérios para diagnóstico histológico de esofagite em 209/227 (92\%). O acréscimo de um caso no conjunto das esofagites ocorreu em função da positividade para $\mathrm{CMV}$ à imunoistoquímica em um caso previamente classificado como sem inflamação.
TABELA 3. Distribuição comparativa dos diagnósticos histopatológicos das esofagites considerados isoladamente ou em associação antes e após a realização de imunoistoquímica

\begin{tabular}{|c|c|c|c|c|c|}
\hline $\begin{array}{l}\text { Diagnóstico - } \\
\text { antes IHQ }\end{array}$ & $\mathrm{n}=227$ & $\%$ & $\begin{array}{l}\text { Diagnóstico - } \\
\text { após IHQ }\end{array}$ & $\mathrm{n}=227$ & $\%$ \\
\hline Sem inflamação & 19 & 8,4 & Sem inflamação & 18 & 7,9 \\
\hline Inespecífico & 97 & 42,9 & Inespecífico & 90 & 39,8 \\
\hline Candida sp & 60 & 26,7 & Candida sp & 56 & 24,9 \\
\hline $\mathrm{CMV}$ & 19 & 8,3 & $\mathrm{CMV}$ & 30 & 13,2 \\
\hline HSV & 4 & 1,7 & HSV & 8 & 3,5 \\
\hline HPV & 4 & 1,7 & HPV & - & - \\
\hline Micobacteriose & 2 & 0,8 & Micobacteriose & 2 & 0,8 \\
\hline Sugestivo vírus & 12 & 5,2 & Sugestivo vírus & 8 & 3,5 \\
\hline Candida sp + CMV & 4 & 1,7 & Candida sp + CMV & 8 & 3,6 \\
\hline Candida sp + HSV & 3 & 1,3 & Candida sp + HSV & 3 & 1,3 \\
\hline $\begin{array}{l}\text { Candida sp + CMV } \\
+\mathrm{HSV}\end{array}$ & - & - & $\begin{array}{l}\text { Candida sp + CMV } \\
+\mathrm{HSV}\end{array}$ & 1 & 0,4 \\
\hline Candida $s p+\mathrm{SV}$ & 3 & 1,3 & Candida $s p+\mathrm{SV}$ & 2 & 0,8 \\
\hline $\mathrm{CMV}+\mathrm{HSV}$ & - & - & $\mathrm{CMV}+\mathrm{HSV}$ & 1 & 0,4 \\
\hline Total & 227 & 100,0 & Total & 227 & 100,0 \\
\hline
\end{tabular}

Além deste caso, as principais mudanças observadas nos diagnósticos após a aplicação da imunoistoquímica decorreram da melhor identificação de infecção pelo CMV, cujos casos de infecção isolada passaram de 19 para 30/227. Também os casos de associação do CMV com outros agentes passaram de 4 para 10/227 (Tabela 3). Houve casos de diagnóstico de CMV somente por colorações de rotina nas quais não foi possível realizar a imunoistoquímica. Esses casos tiveram seus diagnósticos mantidos na soma final.

O HSV I (Figura 1) foi positivo à imunoistoquímica em 6 casos e o HSV II em 13 casos, sendo que em todos os casos onde o HSV I foi identificado, também ocorreu positividade para o HSV II. Da mesma forma que para o $\mathrm{CMV}$, o número de diagnósticos de HSV, isolado ou em associação, aumentou de 7 para 13/227 após a aplicação da imunoistoquímica (Tabela 3).

A identificação do CMV e do HSV à imunoistoquímica reduziu do número de esofagites inespecíficas (97 para 90/227) e de diagnósticos sugestivos de infecção viral (12 para 8/227). Por outro lado, possibilitou melhor caracterização da concomitância de agentes etiológicos nas esofagites, com associação de agentes virais entre si e/ou com Candida sp (10 para 15/227). Desta forma, houve redução do número de casos isolados de Candida sp de 60 para 56/227 (Tabela 3). Não foi encontrada imunorreatividade para os antígenos de EBV, HPV e HIV.

As amostras foram representadas por três fragmentos, ou menos (1-3), em $178(78,5 \%)$ dos casos e por mais de três fragmentos (4-6) em 49 (21,5\%). A distribuição dos diagnósticos histológicos nos dois grupos não apresentou significância estatística.

\section{DISCUSSÃO}

O diagnóstico histológico de esofagite foi encontrado nesta série em $92 \%$ dos casos. Como citado na maioria das séries ${ }^{(4,41,52)}$, a maior parte dos casos é de esofagite grau III (57\%).

A esofagite inespecífica foi o diagnóstico histológico mais freqüente entre as 227 biopsias estudadas $(39,8 \%)$. A maioria destes pacientes apresentava alguma forma de lesão endoscópica, com 
predominância de úlceras e associação significativa $(P=0,013)$. A esofagite inespecífica ulcerada também é a forma mais comum nas grandes séries e, apesar do emprego de técnicas mais específicas e sensíveis, como a hibridização in situ, a "polimerase chain reaction" (PCR) e a cultura, estas lesões permaneceram sem a identificação de um agente etiológico ${ }^{(20,27,28,29,36,49)}$.

Entre os 209 casos de esofagite, a caracterização de um ou mais agentes etiológicos foi feita em 119 casos $(52,3 \%)$. Na maior série estudada, BONACINI et al. ${ }^{(4)}$, relatam a identificação de agente etiológico em $65 \%$ dos casos. Entretanto, esses autores utilizaram, além dos exames histológico e imunoistoquímico, a citologia e cultura o que confere maior sensibilidade aos seus resultados.

A esofagite por Candida $s p$ considerada isoladamente ou em associação (70/209-33,5\%) foi o agente etiológico mais freqüentemente encontrado. $\mathrm{Na}$ literatura, esta forma de esofagite representa cerca de $40 \%$ a $80 \%$ dos casos contudo, os autores utilizam também a citologia e a cultura, como métodos de diagnóstico ${ }^{(5,30)}$. Segundo YOUNG and ELIAS ${ }^{(52)}$, o exame citológico tem maior sensibilidade para o diagnóstico de candidíase que o exame histológico $(95 \% \mathrm{e}$ $70 \%$, respectivamente), sobretudo nas formas leves de infecção. Quanto ao aspecto endoscópico, nas esofagites por Candida $s p$, houve correlação significativa com a presença de placa $(P=0,0001)$ e de enantema $(P=0,05)$. BONACINI et al. ${ }^{(4)}$, também encontraram placas associadas ao diagnóstico de candidíase em $88 \%$ dos casos. Encontrou-se, ainda, concordância entre o diagnóstico endoscópico e histológico de Candida sp $(P=0,0001)$. O diagnóstico endoscópico de candidíase e de placa sugere fortemente o diagnóstico histológico de Candida $s p$.

Em duas grandes séries ${ }^{(4,14)}$, cerca de $25 \%$ dos casos apresentavam a associação de agentes infecciosos, sendo que ocorreram principalmente às custas de Candida sp e de vírus. Na presente série, encontrou-se associação em $6,4 \%$ dos casos (15/227), o que talvez se deva ao fato de não se ter realizado escovado e citologia.

Nas esofagites virais, o agente mais comum foi o CMV, considerado isoladamente em 13,2\% (30/227) e em associação em 4,3\% (10/227), com total de $17,5 \%$ (40/227). Na literatura o CMV também é o agente viral mais freqüente ${ }^{(4,14,51)}$. THEISE et al. ${ }^{(41)}$, encontraram percentuais de $16 \%$ para a $\mathrm{H}-\mathrm{E}$ e $29 \%$ para imunoistoquímica. Esses autores referem ainda que cerca de $20 \%$ dos casos negativos para CMV, na coloração de rotina, são positivos na imunoistoquímica. Nesta série, também foram identificados casos positivos para o CMV à imunoistoquímica que foram normais à histologia e à endoscopia. Observou-se, portanto, que o exame normal não afasta a possibilidade de diagnóstico de CMV pois, mesmo células morfologicamente inalteradas, podem apresentar infecção ativa pelo vírus. Entretanto, a importância clínica desse achado permanece controversa, pois a presença do agente não significa que ele esteja envolvido na patogênese da doença ${ }^{(32)}$. A apresentação endoscópica mais observada foi úlcera, com significância estatística $(P=0,01)$. Outros dados observados foram a relevância da associação entre diagnóstico endoscópico e histopatológico de CMV $(P=0,045) \mathrm{e}$ a associação significativa entre o diagnóstico endoscópico de CMV e o diagnóstico histopatológico de sugestivo de vírus $(P=0,001)$. Apesar de a esofagite por CMV ter como forma mais comum de apresentação a lesão ulcerada, também tem sido relacionada à hiperemia ou até mesmo ao aspecto endoscópico normal do esôfago, como observado também nesta amostra ${ }^{(38,46,47)}$.
A esofagite por HSV foi encontrada isoladamente em 3,5\% e em associação em $2,1 \%$ dos casos, com total de $5,6 \%$ consistindo na segunda infecção viral mais freqüente. Na literatura a freqüência pode chegar a até $7 \%(26,35,50)$. Observou-se predomínio do HSV II em relação ao HSV I e a concomitância das duas infecções em seis casos. Não se identificou infecção por HSV I isoladamente. Outros trabalhos não fazem distinção entre HSV I e HSV II nas esofagites ${ }^{(20,}$ ${ }^{42,43)}$. Entretanto, sabe-se que a infecção por HSV II é encontrada em pacientes com $\operatorname{AIDS}^{(17,22,34)}$. A associação deste agente viral com erosões únicas ou múltiplas $(85,7 \%)$ predominou sobre as lesões ulceradas (42,9\%), consideradas isoladamente ou em associação. Entretanto não houve significância estatística para esses dados.

Os casos de esofagite associada ao HPV não foram confirmados ao exame imunoistoquímico e passaram a ser considerados como inespecíficos. A literatura se refere a esse tipo de infecção, associada à lesão esofagiana, com relatos de poucos $\operatorname{casos}^{(27,37,39,45)}$. Os diagnósticos nessas séries foram confirmados por imunoistoquímica ou PCR.

O diagnóstico de esofagite sugestiva de lesão viral $(5,2 \%)$ foi separado com o objetivo de identificar um grupo de casos que, dentre os inespecíficos, apresentassem características peculiares ao exame histopatológico de rotina que pudessem defini-lo como de etiologia viral. De fato, ao se empregar método mais sensível como a imunoistoquímica, detectou-se positividade para o CMV em um terço (4/12) desses casos. Embora não tenha sido identificada positividade para agentes virais à imunoistoquímica nos outros casos (8/12), estes permaneceram classificados como esofagite sugestiva de infecção viral por apresentarem os critérios descritos por SCHWARTZ et al. ${ }^{(38)}$.

Não se evidenciou no material da presente casuística imunorreatividade para o EBV nem para o HIV. Existem relatos ocasionais destes agentes na literatura, em pequeno número de casos, que são descritos em lesões esofagianas ulceradas e identificados por métodos como cultura, PCR e microscopia eletrônica $^{(2,6,11,24,40)}$, que não foram realizados neste estudo.

Outra forma encontrada esporadicamente é a esofagite por micobactérias $^{(17,21,23)}$. Os dois $(0,8 \%)$ casos em que foi diagnosticado este tipo de esofagite estavam associados a úlceras e à avançada imunodepressão, assim como os descritos na literatura ${ }^{(18)}$.

Quanto ao número de fragmentos, este não influenciou na detecção do agente etiológico nos dois grupos: $\leq 3$ e $>3$ nos quais foi, respectivamente, de 50\% e 48\%. Entretanto, em todos os 15 casos com diagnóstico de associação entre agentes infecciosos, o número de amostras foi $>3$.

\section{CONCLUSÃO}

A esofagite inespecífica foi a forma mais freqüente de apresentação em pacientes com AIDS, sendo a Candida $s p$ o agente etiológico mais comum das lesões esofagianas e se associa à presença de placas. A esofagite por CMV se associa a úlceras e à endoscopia. $\mathrm{O}$ fato do exame endoscópico normal não excluir a possibilidade de esofagite, torna recomendável a realização de biopsias nestes pacientes, além do emprego de técnicas imunoistoquímicas, mesmo diante do exame histológico normal, pois este procedimento auxilia na caracterização de agentes virais como o CMV. O número de fragmentos em uma amostra não contribui para o diagnóstico etiológico das esofagites. 
Vidal APA, Pannain VLN, Bottino AMCF. Esophagitis in patients with acquired human immunodeficiency syndrome. An histological and immunohistochemistry study. Arq Gastroenterol. 2007;44(4):309-14.

ABSTRACT - Background - Almost all patients with acquired immunodeficiency virus syndrome will have gastrointestinal symptoms during the course of their illness. The high prevalence and complications of esophagitis are well documented. Aims - Graduate esophagitis; identify microorganisms like Candida $s p$, cytomegalovirus, herpesvirus and mycobacteria; identify by immunohistochemical staining viral agents cytomegalovirus, herpesvirus I, herpesvirus II, Epstein-Barr Virus, human papilloma virus and human immunodeficiency virus; verify how immunohistochemistry changes the profile of esophagitis; verify the association between the histological and endoscopical findings; verify the relevance of the number of fragments studied in the characterization of the histological agents. Methods - We studied retrospectively esophageal biopsies in 227 patients with acquired immunodeficiency virus syndrome using hematoxylin and eosin, PAS (periodic acid of Schiff), Groccott and Ziehl-Nielsen stains and immunoperoxidase stains to detect opportunistic agents. Endoscopic aspects were studied. Results - The non-specific esophagitis grade III, in the inferior third of the esophagus, was the most frequent type. Candida sp was the most frequent agent, followed by viruses cytomegalovirus, herpesvirus and mycobacteria. The presence of plaque and ulceration suggested the diagnosis of esophageal candidiasis and cytomegalovirus esophagitis. Immunohistochemical allowed the characterization of cytomegalovirus and of herpesvirus in those cases where other techniques could not achieve it, furthermore the cytomegalovirus was also found in histological normal cases, making the use of this technique advisable in routine diagnosis. The herpesvirus I was not found isolated but associated to herpesvirus II. We have not found immunoreactivity for the Epstein-Barr virus and the human immunodeficiency virus. The number of fragments does not seem to influence the detection of the etiologic agent. Conclusion - The endoscopic findings of plaques or ulcers are associated with candidiasis or cytomegalovirus esophagitis. Immunohistochemisty improved the diagnosis of viral infections. It is possible to detect cytomegalovirus infections in endoscopic and histologic normal cases.

HEADINGS - Esophagitis. Acquired immunodefiiciency syndrome. Immunohistochemistry.

\section{REFERÊNCIAS}

1. Apolonio EG, Hoover DR, He Y, Saah AJ, Lyter DW, Detels R, Kaslow RA, Phair JP. Prognostic factors in human immunodeficiency virus positive patients with a CD4 + lymphocyte count $<50$ microL. J Infect Dis. 1955;171:829-36.

2. Bach MC, Howel DA, Valenti AJ, Smith TJ, Winslow DL. Aphthous ulceration of the gastrointestinal tract in patient with the acquired immunodeficiency syndrome. Ann Intern Med. 1990;112:465-6.

3. Bonacini M, Laine L, Gal AA, Lee MH, Martin SE, Strigle S. Prospective evaluation of blind brushing of the esophagus for Candida sp esophagitis in patients with human immunodeficiency virus infection. Am J Gastroenterol. 1990;143:385-9.

4. Bonacini M, Young T, Lane L. The causes of esophageal symptoms in human immunodeficiency virus infection. A prospective study of 110 patients. Arch Inter Med. 1991;151:1567-72.

5. Bonacini M, Young T, Laine L. Histopathology of human immunodeficiency virusassociated esophageal disease. Am J Gastroenterol. 1993;88:549-51.

6. Boulter AW, Saltanpoor N, Swan AV, Birnbaun W, Johnson NW, Teo CG. Risk factors associated with Epstein-Barr virus replication in oral epithelial cells of HIV-infected individuals. AIDS. 1996;10:935-40.

7. Calore EE, Cavaleire JM, Perez NM, Campos-Sales PS, Warnekek O. Esophageal ulcers in AIDS. Pathologica. 1997;89:155-8.

8. Calore EE, Calore NM, Cavaleire JM. Non isotopic in situ hybridization of type of HPV in cervical intraepithelial lesions in patients with AIDS. Arch Gynecol Obstet. 1998;262:75-9.

9. Cappellanes CA, Hashiba K, Brasil HA, D'Assunção MA, Moribe D, Armellini S, Hassegawa RT, Lopes, LH. Role of upper gastrointestinal endoscopy with routine standartized endoscopic biopsy in AIDS. Dig Endosc. 2002;14:152-5.

10. Chaisson RE, Gallant JE, Keruly JC, Moore RD. Impact of opportunistic disease on survival in patients with HIV infection. AIDS. 1998;12:29-33.

11. Chawla SK, Ramani K, Chawea K Lopresti P, Mahadeira P. Giant esophageal ulcers of AIDS: ultrastructural study. Am J Gastroenterol. 1994;89:411-5.

12. Chequer P. A verdadeira face da AIDS no Brasil. J Biochem Mol Biol Biophys. 1997;1:7-10.

13. Chong VH, LIM CC. Human immunodeficiency virus and endoscopy: experience of a general hospital in Singapore. J Gastroenterol Hepatol. 2005;20:722-6.

14. Connolly GM, Hawkins D, Harcourt Webster JN, Parsons PA, Husain AO, Gazzrd BG. Oesophageal symptoms, their causes, treatment and prognosis in patients with the AIDS. Gut. 1989;30:1033-9.

15. Culpepper-Morgan JA, Kotler DP, Sholes JV, Tierney AR. Evaluation of diagnostic criteria for mucosal cytomegalic inclusion disease in the acquired immunedeficiency syndrome. Am J Gastroenterol. 1987;82:1264-70.

16. Do Nascimento MC, Sumita LM, De Souza VA, Panuti CS. Detection and direct typing of HSV in perianal ulcers of patients with AIDS by PCR. J Clin Microbiol. 1988;36:848-9.

17. Dow CJ. Oesophageal tuberculosis: four cases. Gut. 1981;22:234-6.
18. Ferreira MM, Ferrazoli L, Palaci M Salles PS, Medeiros LA, Novoa P, Kiefer CR, Schechtann M, Kriski AL, Johnson WD, Rilley LW, Ferreira Junior OC. Tuberculosis and HIV infection among females inmates in São Paulo, Brazil: a prospective cohort study. J Acquir Immune Defic Syndr Hum Retrovirol. 1996;13:183-7.

19. Gelb A, Miller S. AIDS and gastroenterology. Am J Gastroenterol. 1986;81:619-22.

20. Généreau T, Lortholary O, Bouchaud O, Lacassin F, Vinceneux P, De Truchis P, Jaccard A, Meynard JL, Verdon R, Sereni D, Marche C, Coulaud JP, Guilleven L. Herpes simplex esophagitis in patients with AIDS: report of 34 cases. The cooperative study group on herpetic esophagitis in HIV infection. Clin Inf Dis. 1996;22:296-321.

21. Gray JR, Rabeneck R. Atypical mycobacterial infection of the gastrointestinal tract in AIDS patients. Am J Gastroenterol. 1989;84:1521-4.

22. Hitti J, Watts DH, Burchett SK, Schacker T, Selkes D, Marche C, Coulaud JP, Guilleven L. Herpes simplex virus seropositivity and reaction at delivery among pregnant infected with HIV-1. Am J Obstet Gynecol. 1997;177:450-4.

23. Hoffman ND, Kelly C, Futterman D. Tuberculosis infection in human immunodeficiency virus-positive adolescents and young adults: a New York City cohort. Pediatrics. 1996;97:198-230.

24. Housset C, Boucher O, Girard PM, Leibowilch J, Saimot AG, Brechot C, Marche C. Immunohistochemical evidence for HIV 1 infection of liver Kupffer cells. Hum Pathol. 1990;21:404-8.

25. Kazlow PG, Shah K, Benkov KJ, Dische R, Leleiko NS. Oesophageal cryptosporidiosis in a child with acquired immunodeficiency syndrome. Gastroenterology. 1986;91:1301-3.

26. Keh WC, Gerber MA. In situ hybridization for cytomegalovirus DNA in AIDS patients. Am J Pathol. 1988;131:490-6.

27. Kitchen VS, Helbert M, Francis ND, Logan RP, Lewis FA, Boylston NA, Pinching AJ, Harris JR. Epstein Barr virus associated oesophageal ulcers in AIDS. Gut 1990;31:1223-5.

28. Kotler DP, Wilson CS, Haroutiounian G, Fox CH. Detection of immunodeficiency virus 1 by 35 S-RNA in situ hibridization in solitary esophageal ulcers in two patients with AIDS. Am J Gastroenterol. 1989;84:313-7.

29. Kotler DP, Reka S, Orestein JM, Fox CH. Chronic idiopathic esophageal ulceration in the AIDS. J Clin Gastroenterol. 1992;15:284-7.

30. Malebranche R, Arnoux E, Guerin JM, Pierre GD, Laroche AC, Dean-Guichard C, Elie R, Morisset PH, Spira T, Manderlle R. AIDS with severe manifestations in Haiti. Lancet. 1983;180:873-7.

31. Mocroft A, Ledergerber C, Katlama OK, Kirk O, Reiss P, MonforteAA, Knysz B, Dietrich M, PhillipisAN, Ludgren JD. Decline in the AIDS and death rates in the EuroSIDA study: an observational study. Lancet. 2003;362:22-9.

32. Mönkemüller KE, Wilcox CM. Diagnosis of esophageal ulcers in acquired immunodeficiency syndrome. Semin Gastrointest Dis. 1999;10:85-92.

33. Mönkemüller KE, Call SA, Lazenby AJ, Wilcox M. Declinig prevalence of opportunistic gastrointestinal disease in the era of combination antiretroviral therapy. Am J Gastroenterol. 2000;95:457-62.

34. Nash G, Ross JS. Herpetic esophagitis: a common cause of oesophageal ulceration. Hum Pathol. 1974;5:339-45. 
35. Robey S, Gage WR, Rothenberg R. Comparison of immunoperoxidase and DNA ISH techniques in the diagnosis of cytomegalovirus colitis. Am J Clin Pathol. 1988;89:666-70.

36. Schafer RW, Bloch AB, Larkin C. Predictors of survival in HIV infected tuberculosis patients. AIDS. 1996;10:269-72.

37. Schechter M, Pannain VL, Oliveira AV. Papillomavirus associated with esophageal ulceration in patients with AIDS. AIDS. 1991;2:238-41.

38. Schwartz DA, Wilcox CM. Atypical CMV inclusions in gastrointestinal biopsy specimens from patients with AIDS: diagnostic role of in situ hibridization. Hum Pathol. 1992;23:1019-21.

39. Shah KV, Howley, PM. Papillomavirus. In FIELDS virology 3a. ed. Philadelphia: Lippincott-Raven;1996. p.2077-109.

40. Smith PD, Eis MS, Manischewitz JF, Gill VJ, Maser H, Fox CF. Esophageal disease in AIDS is associated with pathologic processes rather than mucosal HIV type1. J Infect Dis. 1993;67:547-52.

41. Theise ND, Rotterdam H, Dieterich D. Cytomegalovirus esophagitis in AIDS: diagnosis by endoscopic biopsy. Am J Gastroenterol. 1991;86:1123-6.

42. Tomita T, Chiga M, Lenaham M, Balachandram N. Identification of the herpes simplex virus infection by immunoperoxidase and hybridization methods. Virchows Arch Pathol Anat Histopathol. 1991;419:99-105.

43. Tomita T, Garcia F, Mowry M. Herpes simplex hepatitis before and after acyclovir treatment. Immunohistochemical and in situ hybridization study. Arch Pathol Lab Med. 1992;115:173-7.

44. Triantos D, Leao JC, Porter Sr, Scully CM, Teo CG. Tissue distribution of Epstein Barr virus genotypes in hosts coinfected by HIV. AIDS. 1998;12:2141-6.
45. Trottier AM, Coutlee F, Leduc R, Ghattas G, Toma E, Allane G, Gaboury L, Ghadirian P. Human immunodeficiency virus infection is a major risk factor for detection of human papillomavirus DNA in esophageal brushings. Clin Infect Dis 1997;24:565-9.

46. Villar LA, Massanari RM, Miltros FA. Cytomegalovirus infection with acute erosive esophagitis. Am J Med. 1984;76:924-8.

47. Weber JN, Thom S, Barrinson I, Unwin R, Forester S, Jeffries DJ, Boyesten A, Pinching A. Cytomegalovirus colitis and oesophageal ulceration in the contest of AIDS: clinical manifestations and preliminary report of treatment with foscarnet. Gut. 1987;28:482-7.

48. Wilbur DC, Reichman RC, Stoler MH. Detection of infection by human papillomavirus in genital condylomata. Am J Clin Pathol. 1988;89:505-10.

49. Wilcox CM, Zaki SR, Coffiles LM, Geer PW, Schwartz DA. Evaluation of idiopathic esophageal ulceration for human immunodeficiency virus. Mod Pathol. 1995;8:568-72.

50. Wilcox CM, Straub RF, Scharwtz DA. Prospective evaluation of biopsy number for the diagnosis of viral esophagitis in patients with infection and esophageal ulcer Gastrointest Endosc. 1996;44:587-93.

51. Wilcox CM. Esophageal strictures and ulcerative esophagitis. Am J Gastroenterol. 1999;94:339-43.

52. Young JA, Elias E. Gastro-oesophageal candidiasis: diagnosis by brush cytology. J Clin Pathol. 1985;38:293-6.

53. Zaidi, SA., Cervia, JS. Diagnosis and management of infectious esophagitis associated with HIV infection. J Int Ass Physicians AIDS Care. 2002;1:53-62.

Recebido em 30/11/2006.

Aprovado em 4/5/2007. 